\title{
ESTIMATION OF THE FISSION PRODUCTS, ACTINIDES AND TRITIUM OF HTR-10
}

\author{
HYEDONG JEONG* and SOON HEUNG CHANG \\ Korea Advanced Institute of Science and Technology, Dept. of Nuclear and Quantum Engineering, \\ 373-1, Guseong-dong, Yuseong-gu, Daejeon, 305-701, Korea \\ ${ }^{*}$ Corresponding author. E-mail : hyedong@kaist.ac.kr
}

Received September 1, 2008

Accepted for Publication January 7, 2009

\begin{abstract}
Given the evolution of High-Temperature Gas-cooled Reactor (HTGR) designs, the source terms for licensing must be developed. There are three potential source terms: fission products, actinides in the fuel and tritium in the coolant. It is necessary to provide first an inventory of the source terms under normal operations. An analysis of source terms has yet to be performed for HTGRs. The previous code, which can estimate the inventory of the source terms for LWRs, cannot be used for HTGRs because the general data of a typical neutron cross-section and flux has not been developed. Thus, this paper uses a combination of the MCNP, ORIGEN, and MONTETEBURNS codes for an estimation of the source terms. A method in which the HTR-10 core is constructed using the unit lattice of a body-centered cubic is developed for core modeling. Based on this modeling method by MCNP, the generation of fission products, actinides and tritium with an increase in the burnup ratio is simulated. The model developed by MCNP appears feasible through a comparison with models developed in previous studies. Continuous fuel management is divided into five periods for the feeding and discharging of fuel pebbles. This discrete fuel management scheme is employed using the MONTEBURNS code. Finally, the work is investigated for 22 isotope fission products of nuclides, 22 actinides in the core, and tritium in the coolant. The activities are mainly distributed within the range of $10^{15} \sim 10^{17} \mathrm{~Bq}$ in the equilibrium core of HTR-10. The results appear to be highly probable, and they would be informative when the spent fuel of HTGRs is taken into account. The tritium inventory in the primary coolant is also taken into account without a helium purification system. This article can lay a foundation for future work on analyses of source terms as a platform for safety assessment in HTGRs.
\end{abstract}

KEYWORDS : Source Term, Fission Product, HTGR

\section{INTRODUCTION}

The design of high-temperature gas-cooled reactors (HTGRs) has evolved and the safety requirements have been defined [1]; accordingly, the source terms that form the basis of licensing must be developed. Nuclear systems require a reliable inventory of fission products for safety and waste management purposes. There has been an increasing amount of interest in performing burnupdependent core analyses, including depletion calculations of the inventory of nuclides. The main objectives of depletion calculations are to provide as much detail as possible regarding the composition of irradiated HTGR fuel and to quantify the radioactive inventory for potential source terms.

In order to understand the nature of severe accidents in a HTGR, it is necessary to provide the potential source terms first under normal operations. An analysis of source terms has yet to be performed for HTGRs. Researchers have studied light water reactors (LWR) [2] extensively and developed various tools of evaluation, such as ORIGEN and CITATION, for those types of reactors. However, these tools are not adoptable, as the typical neutron cross-section data and flux information, together determine the generation of source terms, are not supported in the previous tools. Few arguments have been made for HTGRs, and there is a paucity of experimental measurement data and a lack of simulation results pertaining to unpublished code packages. In particular, a general code of estimation for the source term of HTGRs has not been provided despite the fact that HTGRs are considered to be generation-IV reactors.

Therefore, the purpose of this paper is to calculate a source term inventory of the core by generating information pertaining to the neutron cross-section and flux, particularly on the subject of HTR-10 as a reference reactor, under normal operation. 


\section{METHOD}

\subsection{Code Description}

Calculations for an inventory estimation of source term are usually performed within the context of the requirements of reactor physics studies, such as in-core fuel management and fuel cycle analysis simulations. Full-core neutronics calculations are strongly dependent on the fuel distribution, the structural materials and the geometry of the core. Due to its importance to accurate calculations in the field of reactor physics, the neutron cross-sections data and flux should be generated according to the core.

Concerning widely used reactors such as LWRs, there are the standard libraries of the Oak Ridge Isotope Generation and depletion (ORIGEN) code which include one-group spectral averaged cross-sections. Spectralaveraged neutron cross-sections are required to solve burnup equations. The spectral-averaged cross-sections depend on the burnup ratio due to changes in the isotope concentrations of the fuel assembly with the burnup. When creating a cross-section library, the spectrum with burnup should be considered. In case of a HTGR, no data library exists; thus, researchers must formulate their own libraries according to the given situation. Table 1 [3] illustrates a simple reason that explains why existing libraries cannot be employed. Within the traditional LWR fuel assembly, the mean free path for both thermal and epithermal neutrons in water is less than $0.8 \mathrm{~cm}$, which is much smaller than the width of the LWR fuel assembly, which is $21.45 \mathrm{~cm}$. This indicates that most of the neutrons that originate from one fuel assembly are thermalized locally inside the fuel assembly itself. Thus, the neutron spectrum within the fuel assembly depends on the burnup of the fuel assembly itself. However, the mean free path in graphite is approximately $2.4 \mathrm{~cm}$, which is similar to the fuel sphere radius, $3 \mathrm{~cm}$, for pebble bed reactors ( $\mathrm{PBRs}$ ). Hence, the neutrons are very likely to escape from the originating fuel sphere and become thermalized in neighboring fuel spheres. This implies that the neutron cross-section is mostly determined by the burnup of the surrounding spheres. Therefore, in this study, a neutron cross-section library for PBRs is generated using a Monte Carlo method.

Appropriate computational codes and nuclear data should be used to address this flux generation problem. It may be useful to start by examining the approved codes. Several burnup calculation codes have been developed, and these can be found in the Nuclear Energy Agency data bank. The code combination of MCNP, ORIGEN and MONTEBURNS, which is based on the Monte Carlo method, was chosen for a depletion calculation in the current work, as this code set is more reliable and applicable for HTGRs [4]. The Monte Carlo N Particle transport (MCNP) code is a three-dimensional Monte Carlo transport code that can be used for calculations involving neutron, photon, electron, or coupled neutron/photon/electron transport. It is also capable of calculating the Eigen values for critical systems [5]. The ORIGEN code is a zerodimension isotope generation and depletion code that is used to calculate the buildup, decay, and processing of radioactive materials [6]. ORIGEN solves the Bateman equation for the concentration $\mathrm{N}_{i}$ of isotope $i$ in a material subject to neutron irradiation. The general differential equation for depletion can be written as follows:

$$
\frac{d N_{i}}{d t}=\sum_{j=1}^{N} \delta_{i j} \lambda_{j} N_{i}+\sum_{k=1}^{N} f_{i k} N_{k} \int \varphi(E, t) \sigma_{k}(E) d E-\left(\lambda_{i}+\int \varphi(E, t) \sigma_{i}(E) d E\right) N_{i}
$$

Here, $\lambda_{j}=$ the decay constant $[/ \mathrm{sec}]$,

$\varphi(E, t)=$ the energy-dependent neutron flux $\left[\# / \mathrm{cm}^{2} \cdot \mathrm{sec}\right]$,

$\sigma_{i}=$ the neutron absorption cross-section of the nuclide $i\left[\mathrm{~cm}^{2}\right]$.

MONTEBURNS is a utility code that connects MCNP to ORIGEN and calculates depletion based on the MCNP model. MCNP calculates the one-group microscopic crosssections and fluxes that are used by ORIGEN in depletion calculations. After performing a depletion calculation, MONTEBURNS extracts the inventory of fission materials from the ORIGEN output file and updates the material compositions automatically in the MCNP input file for

Table 1. The Mean Free Path of the Neutron is Smaller than the Radius of a Pebble Due to a Graphite Moderator

\begin{tabular}{cccc}
\hline & Quantity & Water & Graphite \\
\hline $\begin{array}{c}\text { Thermal } \\
\text { neutron } \\
(\sim 0.025 \mathrm{eV})\end{array}$ & $\sum_{\mathrm{a}}(1 / \mathrm{m})$ & 2.2 & 0.029 \\
\cline { 2 - 4 } & $\sum_{s}(1 / \mathrm{m})$ & 345.0 & 41.0 \\
\hline $\begin{array}{c}\text { Epithermal } \\
\text { neutron } \\
(\sim 0.1 \mathrm{eV})\end{array}$ & $\sum_{\mathrm{a}}(1 / \mathrm{m})$ & 0.0029 & 0.024 \\
\cline { 2 - 4 } & Mean free path $(\mathrm{m})$ & 2.1 & 0.029 \\
\hline
\end{tabular}


the next burnup step [7]. The workflow by this code set is explained in Fig. 1.

\subsection{Core Modeling}

There are many HTGRs, but the core of HTR-10 in China, which is a type of PBR, was selected as a reference

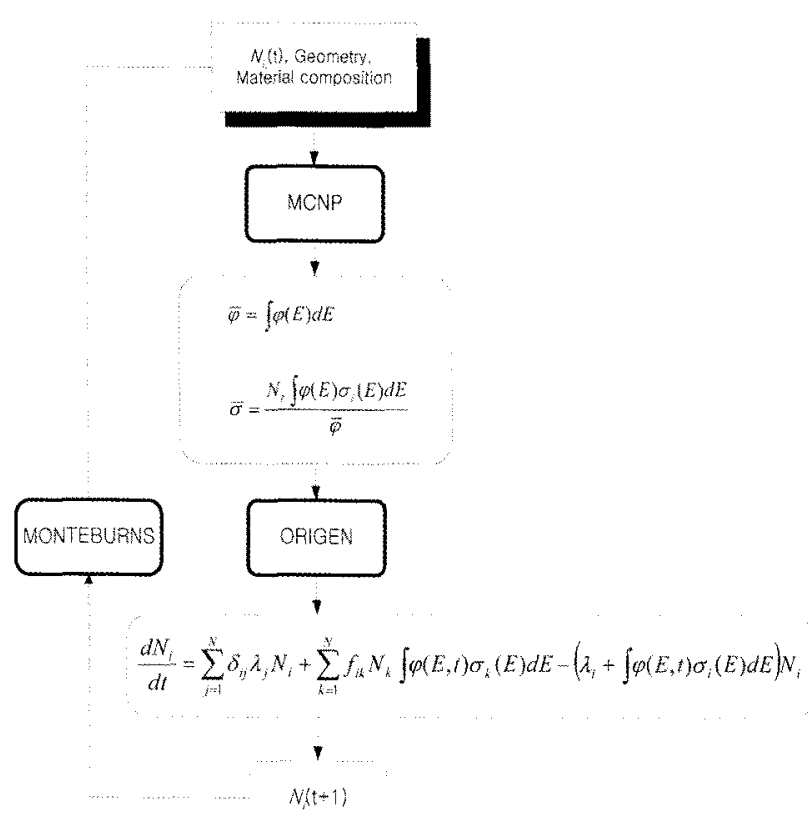

Fig. 1. Workflow of a Burnup Calculation Using with the MCNP-ORIGEN-MONTEBURNS Code benchmark model. IAEA recently published the benchmark problem sets [8], and this sufficient information serves as the guideline to model the HTGR core. The design parameters of HTR -10 are summarized in Table 2. This study models the core through a more accurate approach and deals with some of the core physics benchmark problems proposed for the HTR-10 initial core.

A double-heterogeneous MCNP spherical model was constructed to simulate a core. The first heterogeneity was in a tri-isotropic coated fuel particle (TRISO) forming a fuel pebble and the second heterogeneity was implemented in the lattice of the reactor core. Detailed information of

Table 2. Design Parameters of HTR 10

\begin{tabular}{l|c}
\hline Reactor thermal power $[\mathrm{MW}]$ & 10 \\
\hline Primary helium pressure & 3.0 \\
\hline Reactor core diameter [cm] & 180 \\
\hline Core height $[\mathrm{cm}]$ & 197 \\
\hline Number of control rods in side reflector & 10 \\
\hline Number of absorber ball units in side reflector & 7 \\
\hline Nuclear fuel & $\mathrm{UO}_{2}$ \\
\hline Heavy metal loading per fuel sphere [g] & 5 \\
\hline TRISO in Pebble & 8335 \\
\hline Enrichment of fresh fuel element [wt $\%]$ & 17 \\
\hline Number of fuel elements in an equilibrium core & 27,000 \\
\hline
\end{tabular}

Table 3. Double Heterogeneity Classification for Core Modeling

\begin{tabular}{|c|c|c|}
\hline & Parameter & Dimension $[\mathrm{cm}]$ \\
\hline \multirow{9}{*}{ Heterogeneity for Pebble } & Fuel kemel radius & 0.025 \\
\hline & Carbon buffer thickness & 0.009 \\
\hline & Inner pyro-carbon thickness & 0.004 \\
\hline & Silicon carbide thickness & 0.0035 \\
\hline & Outer pyro-carbon thickness & 0.004 \\
\hline & TRISO lattice width & 0.0976 \\
\hline & No. of TRISO in pebble [\#] & 8335 \\
\hline & Fuel zone & 2.5 \\
\hline & Pebble graphite shell thickness & 0.5 \\
\hline \multirow{4}{*}{ Heterogeneity for Core } & Filling fraction [unit-less] (reference) & $0.65(\sim 0.61)$ \\
\hline & BCC lattice width & 6.724 \\
\hline & Fuel : Moderator [unit-less] & $57: 43$ \\
\hline & Radius of a moderator for adjusting the ratio & 2.731 \\
\hline
\end{tabular}




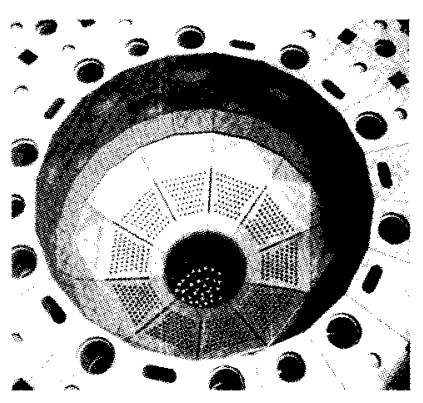

(a) Actual core of HTR-10

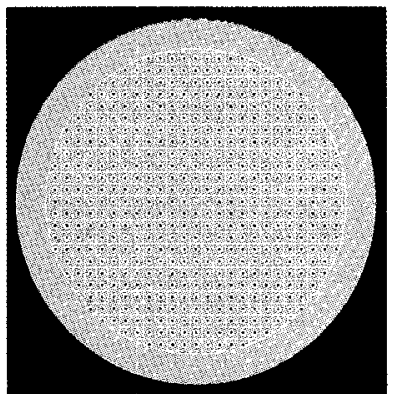

(c) Pebble

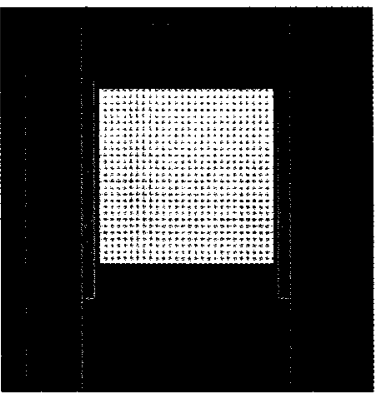

(b) Longitudinal view of the core

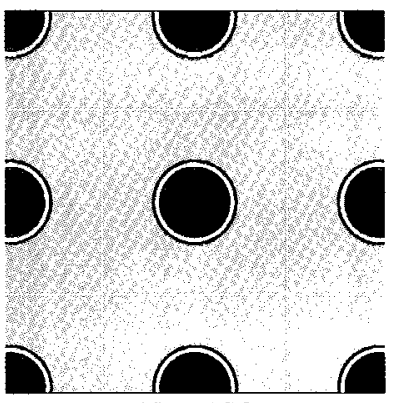

(d) TRISO

Fig. 2. Double Heterogeneous Core Modeling by MCNP

the double heterogeneities is listed in Table 3.

Each TRISO was distributed in the fueled region of the fuel pebbles in the form of a simple-cubic lattice, and the basic unit of the core lattice was constructed in the form of a body-centered cubic (BCC) structure with moderator pebbles of a reduced diameter, which reproduces the specified fuel-to-moderator pebble ratio of 57:43. The double-heterogeneous geometric configurations of the HTR-10 model are shown in Fig. 2, and the typical structure of lattice cells with fuel and a moderator pebble is shown in Fig. 3.

\subsection{Fuel Management with an Increase of Burnup}

Although shorter burnup intervals can increase the level of accuracy, this benefit requires additional execution time. To balance the tradeoff between accuracy and execution time, it is common to execute MONTEBURNS using, typically, five GWD/MTU burnup steps [4]. This study used a burnup interval of approximately $3.7 \mathrm{GWD} / \mathrm{MTU}$ and 23 burnup steps.

The fuel management scheme during operation of up to $80 \mathrm{GWD} / \mathrm{MTU}$ by Yang et al. [9], which is described in Fig. 4, was employed. The continuous fuel management shown in Fig. 4 is divided into the five periods discretely for the MONTEBURNS simulation. The initial 0.43 ratio of the moderator gradually decreases in the core, and only fuel pebbles eventually remain by the fifth stage. It appears reasonable to assume that every fuel pebble should be

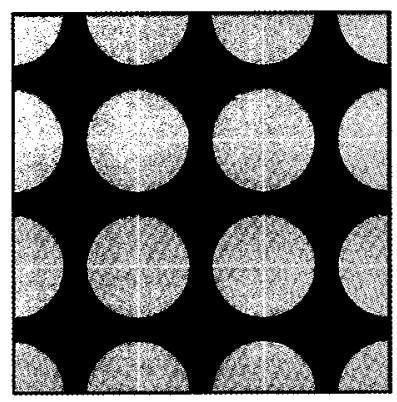

(a) Top face of the lattice is $3.36 \mathrm{~cm}$ above a zero level

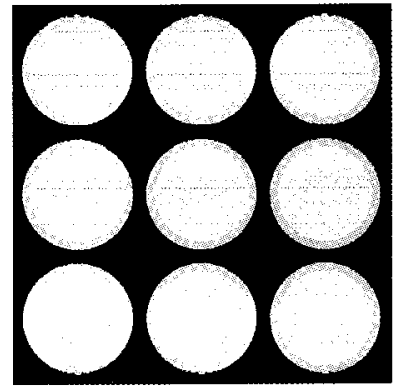

(c) Cross-sectional view at a zero level

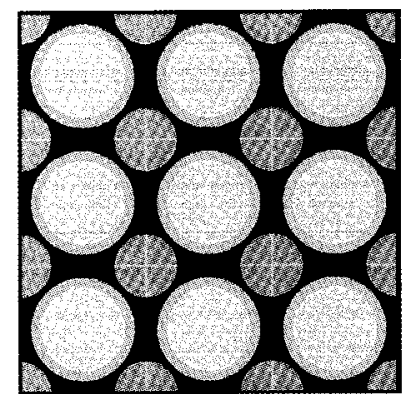

(b) $1.2 \mathrm{~cm}$ above a zero level

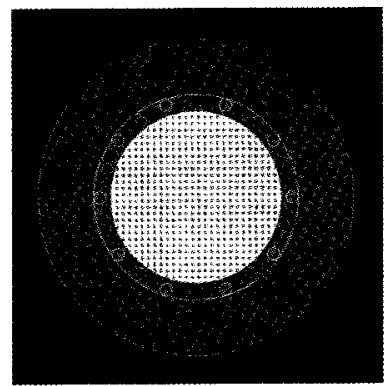

(d) Full core overview
Fig. 3. Four Cross-sectional Images of a BCC Core Lattice. Gray Denotes the Moderator and the Other Areas are the Fuel; (a) Only Moderators, (b) Fuels and Moderators, (c) Only Fuels are Shown

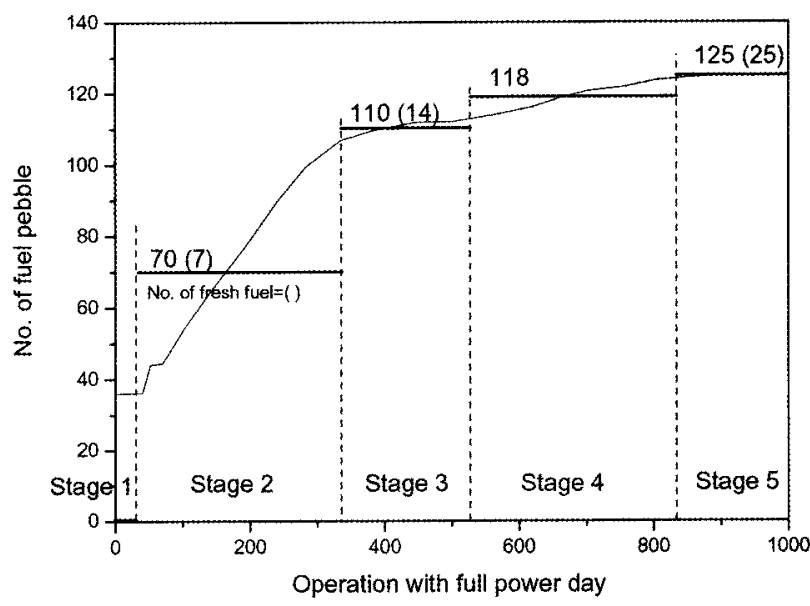

Fig. 4. HTR-10 Fuel Management with Time [9]. The Dotted Lines are the Fuel Supply Intervals

burnt-up at $80 \mathrm{GWD} / \mathrm{MTU}$ at the end of the cycle. The PBR design was designed to have a continuous reloading scheme in which unloaded fuel spheres, which have not reached the target burnup amount, are returned to the top of the core. 


\subsection{Coolant Management for Tritium}

Tritium is considered as the important source term because it can permeate into and through materials, especially metals. This permeation on the heat exchanger causes problems with hydrogen production. Moreover, because tritium behaves chemically as hydrogen, it can undergo isotope exchange reactions with hydrogen-containing chemicals (e.g., $\mathrm{H}_{2} \mathrm{O}, \mathrm{H}_{2}$, or $\mathrm{CH}_{4}$ ).

Tritium is produced in reactors by neutron absorption in boron and lithium in the coolant. The reaction is generated by the following mechanisms [10]:

$$
\begin{aligned}
& { }_{3}^{6} \mathrm{Li}+{ }_{0}^{1} n \rightarrow{ }_{3}^{6} \mathrm{He}+{ }_{1}^{3} \mathrm{H} \\
& { }_{3}^{7} \mathrm{Li}+{ }_{0}^{1} n \rightarrow{ }_{2}^{5} \mathrm{He}+{ }_{1}^{3} \mathrm{H} \\
& { }_{3}^{7} \mathrm{Li}+{ }_{0}^{1} n \rightarrow{ }_{0}^{1} n+{ }_{2}^{4} \mathrm{He}+{ }_{3}^{3} \mathrm{H} \\
{ }_{5}^{10} \mathrm{~B}+{ }_{0}^{1} n \rightarrow{ }_{2}^{4} \mathrm{He}+{ }_{3}^{7} \mathrm{Li}, \quad{ }_{3}^{7} \mathrm{Li}+{ }_{0}^{1} n \rightarrow{ }_{2}^{5} \mathrm{He}+{ }_{1}^{3} \mathrm{H} & { }_{5}^{10} \mathrm{~B}+{ }_{0}^{1} n \rightarrow 2_{2}^{4} \mathrm{He}+{ }_{1}^{3} \mathrm{H} \\
& { }_{5}^{11} \mathrm{~B}+{ }_{0}^{1} n \rightarrow{ }_{4}^{9} \mathrm{Be}++_{1}^{3} \mathrm{H}
\end{aligned}
$$

As the concentration of lithium is not known, only boron is considered in equation (3). The reaction of lithium in equation (2) will be assessed in a future study. Boron is not present in coolant but exists in moderators. It was assumed that the dust from the moderators to the coolant was dispersed at a concentration of $0.125 \mathrm{ppm}$ [11].

Additionally, tritium generation in the coolant is caused by graphite and hydrogen from coolant impurities of $\mathrm{CH}_{4}, \mathrm{H}_{2} \mathrm{O}$, and $\mathrm{H}_{2}$ :

$$
\begin{aligned}
& { }_{6}^{12} \mathrm{C}+{ }_{0}^{1} n \rightarrow{ }_{2}^{4} \mathrm{He}+{ }_{4}^{9} \mathrm{Be}, \\
& { }_{4}^{9} \mathrm{Be}+{ }_{0}^{1} n \rightarrow{ }_{2}^{4} \mathrm{He}+{ }_{3}^{6} \mathrm{Li}, \quad{ }_{3}^{6} \mathrm{Li}+{ }_{0}^{1} n \rightarrow{ }_{2}^{4} \mathrm{He}+{ }_{1}^{3} \mathrm{H} \\
& { }_{1}^{2} \mathrm{H}+{ }_{0}^{1} n \rightarrow{ }_{1}^{3} \mathrm{H}
\end{aligned}
$$

The anticipated inventories of gaseous impurities in the coolant under normal operation are: $\mathrm{H} 2 \mathrm{O} \leq 0.2 \mathrm{ppm}, \mathrm{CO}$ $\leq 3 \mathrm{ppm}, \mathrm{N}_{2} \leq 1 \mathrm{ppm}, \mathrm{H}_{2} \leq 3 \mathrm{ppm}, \mathrm{CH}_{4} \leq 1 \mathrm{ppm}$ [12].

Tritium is also produced in helium coolant, and ${ }^{3} \mathrm{He}$ exists in the amount of $0.000137 \%$ in natural ${ }^{4} \mathrm{He}$.

$$
{ }_{2}^{3} \mathrm{He}+{ }_{0}^{1} n \rightarrow{ }_{1}^{1} H+{ }_{1}^{3} H
$$

In equilibrium after the coolant has many passes around the primary circuit, the inventory of tritium must be equal to $\alpha$; equation (6) shows this simple process:

$$
\alpha=\frac{\sum_{a c t} \phi_{a v}\left(1-e^{-\lambda t_{i}}\right)}{\left(1-e^{-\lambda\left(t_{i}+t_{0}\right)}\right)} \approx \Sigma_{a c t} \phi_{a v} \frac{t_{i}}{t_{i}+t_{o}} \approx \sum_{a c t} \phi_{a v} \frac{V_{\text {core }}}{V_{\text {total }}}
$$

Here, $\sum_{a c t}=$ the average macroscopic activation crosssection $\left[\mathrm{cm}^{-1}\right]$,

$\varphi_{a v}=$ the average neutron flux $\left[\# / \mathrm{cm}^{2} \cdot \mathrm{sec}\right]$,

$\lambda=$ the decay constant $[/ \mathrm{sec}]$

$t_{i}=$ the time the coolant spends in the reactor flux [in sec],

$t_{o}=$ the time the coolant spending in the outer circuit with no flux [sec],

$V_{\text {core }} / V_{\text {total }}=$ the volume ratio of the core to the total.

The values of $\sum_{a c t}$ and $\varphi_{a v}$ are calculated by MCNP and the depletion calculation is done using ORIGEN. The volume ratio and coolant purification fraction are assumed to be 0.0214 [12] and $1 \%$ /day [11], respectively.

\section{RESULT}

\subsection{Validation of MCNP Modeling}

The validity of MCNP modeling work can be determined by examining the multiplication factor, $\mathrm{k}_{\mathrm{cff}}$, in conjunction with the core height. The method of evaluating whether the modeling works is explained in an IAEA report involving HTR-10 benchmark problems [8], and the question of validation is explained in terms of the estimation of the critical height. A BCC lattice to model the core is used, and the radius of a moderator sphere must be smaller than the original to match the actual fuel-to-moderator ratio, in this case $2.731 \mathrm{~cm}$. Table 4 , which compares the results of previous studies and those of the current, confirms that the current modeling provides feasible results. Fig. 5 also shows a comparison of the results of the MCNP simulation with previous studies under the same conditions. The most of the calculation results yield a similar trend. Therefore, these results reflect that the current work can estimate the critical height of the core, showing that the MCNP modeling of the HTR-10 core in the current study is viable.

Table 4. Comparison of the Critical Height [8]

\begin{tabular}{c|c|c}
\hline Institution & Method/Code & Critical height $[\mathrm{cm}]$ \\
\hline INET & Experimental & $\mathbf{1 2 3 . 0 6}$ \\
\hline INET & Diffusion\&Transport/VSOP94 & 125.80 \\
\hline HU & Diffusion\&Transport/VSOP94 & 119.27 \\
\hline NRG & Diffusion \& Transport/PANTHER & 122.1 \\
\hline FZJ & Monte Carlo/TRIPOLI4 & 117.37 \\
\hline MIT & Monte Carlo/MCNP4B & 127.5 \\
\hline KAIST & Monte Carlo/MCNP & 120.95 \\
\hline \multicolumn{2}{|c}{}
\end{tabular}




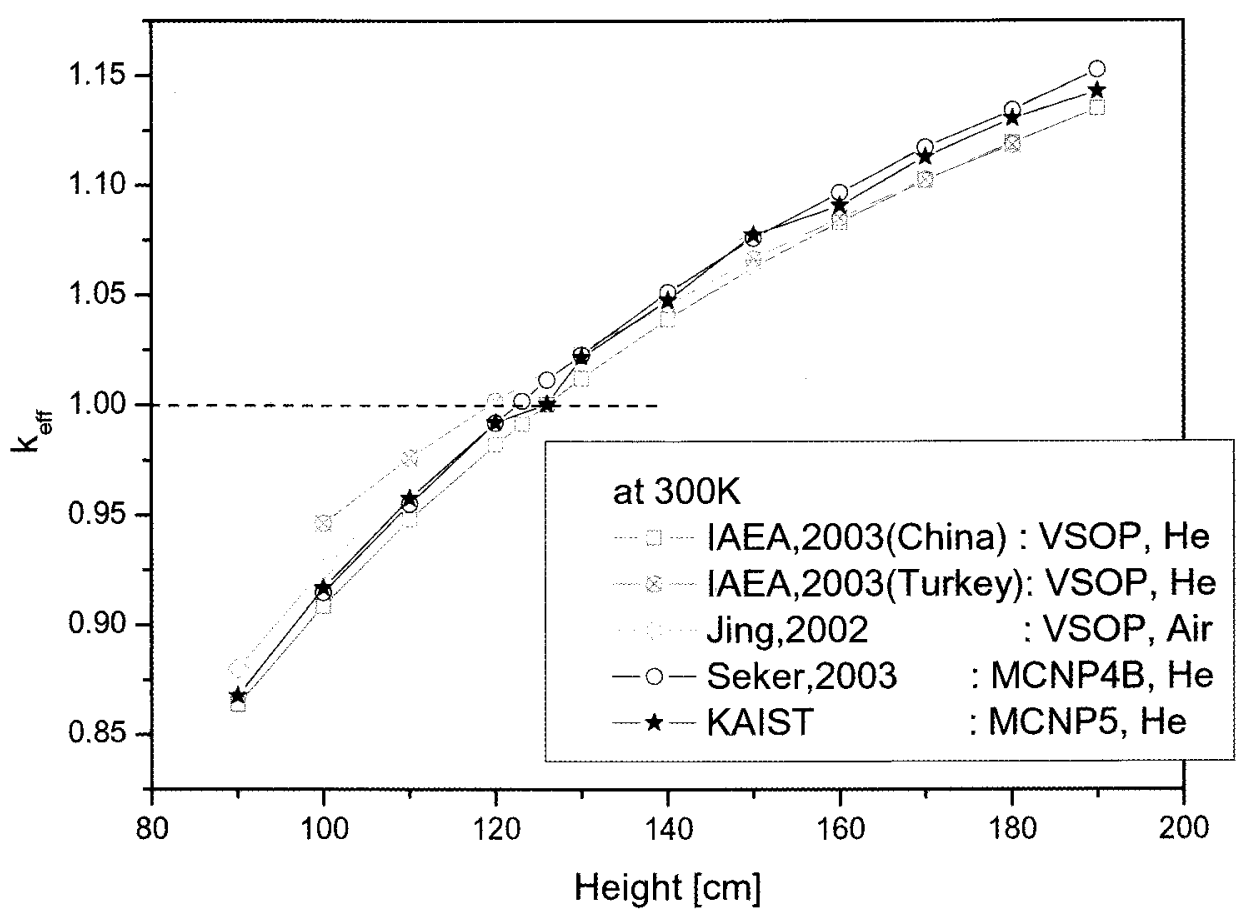

Fig. 5. Variation of $k_{\text {eff }}$ with Core Loading $[8,13]$

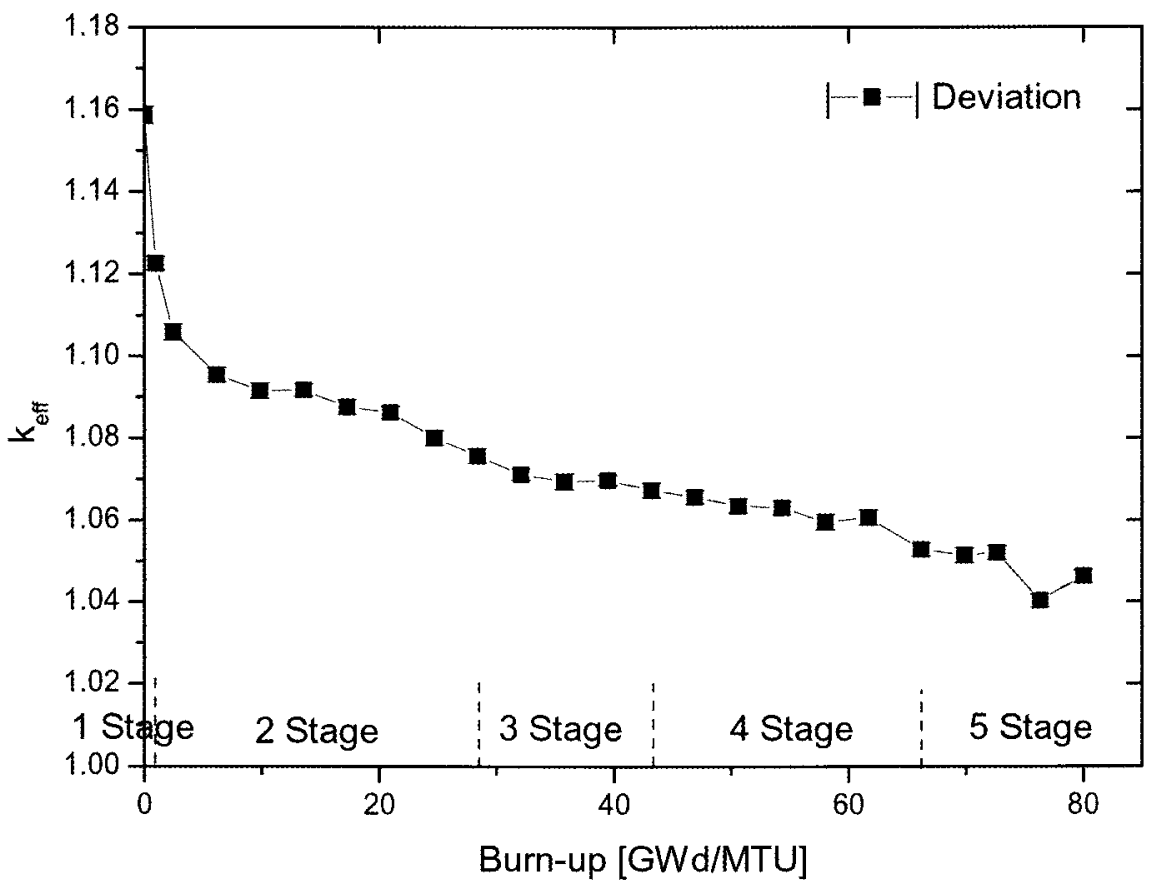

Fig. 6. Reactivity Variation with Time

\subsection{Fission Product Inventory}

As shown in Fig. 6, the reactor core maintains supercriticality and is operated under full power. As time goes on with the fuel feed and discharge management described in Fig. $4, k_{\text {eff }}$ gradually declines. The occasional swing under simulated operation may be due to the failure to 


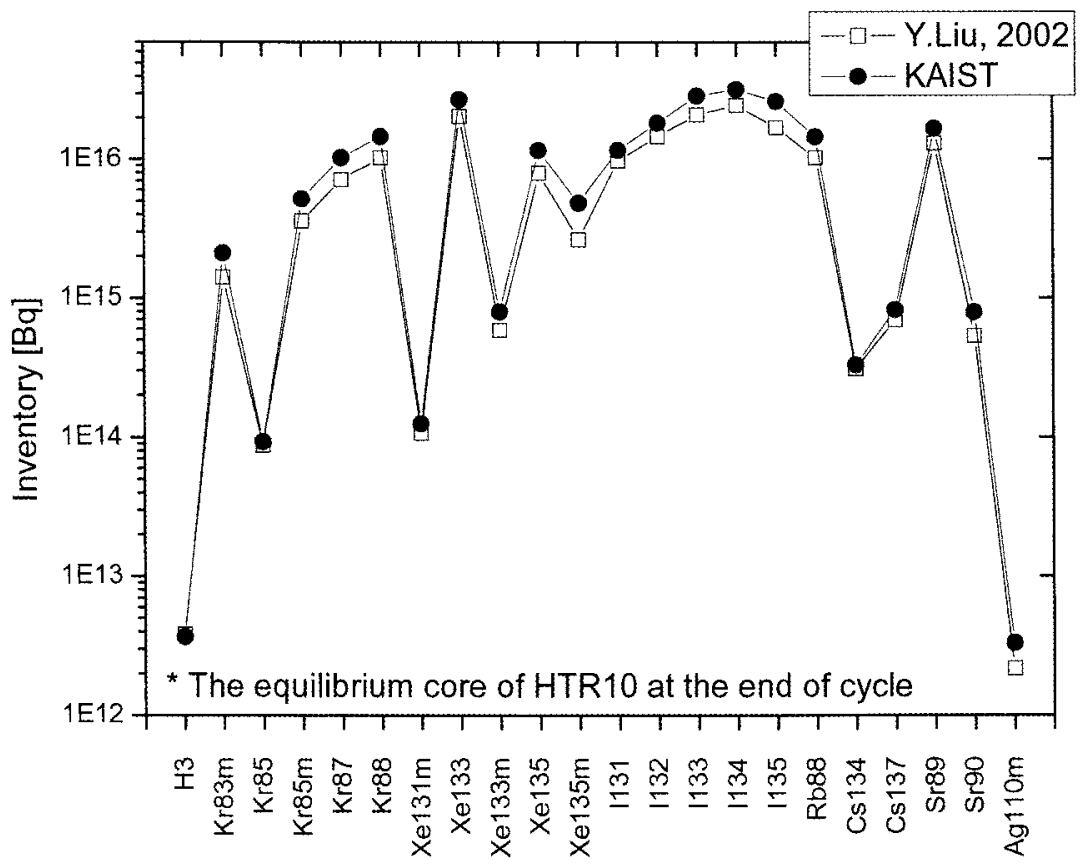

Fig. 7. Comparison of the Inventory of Fission Products [14]

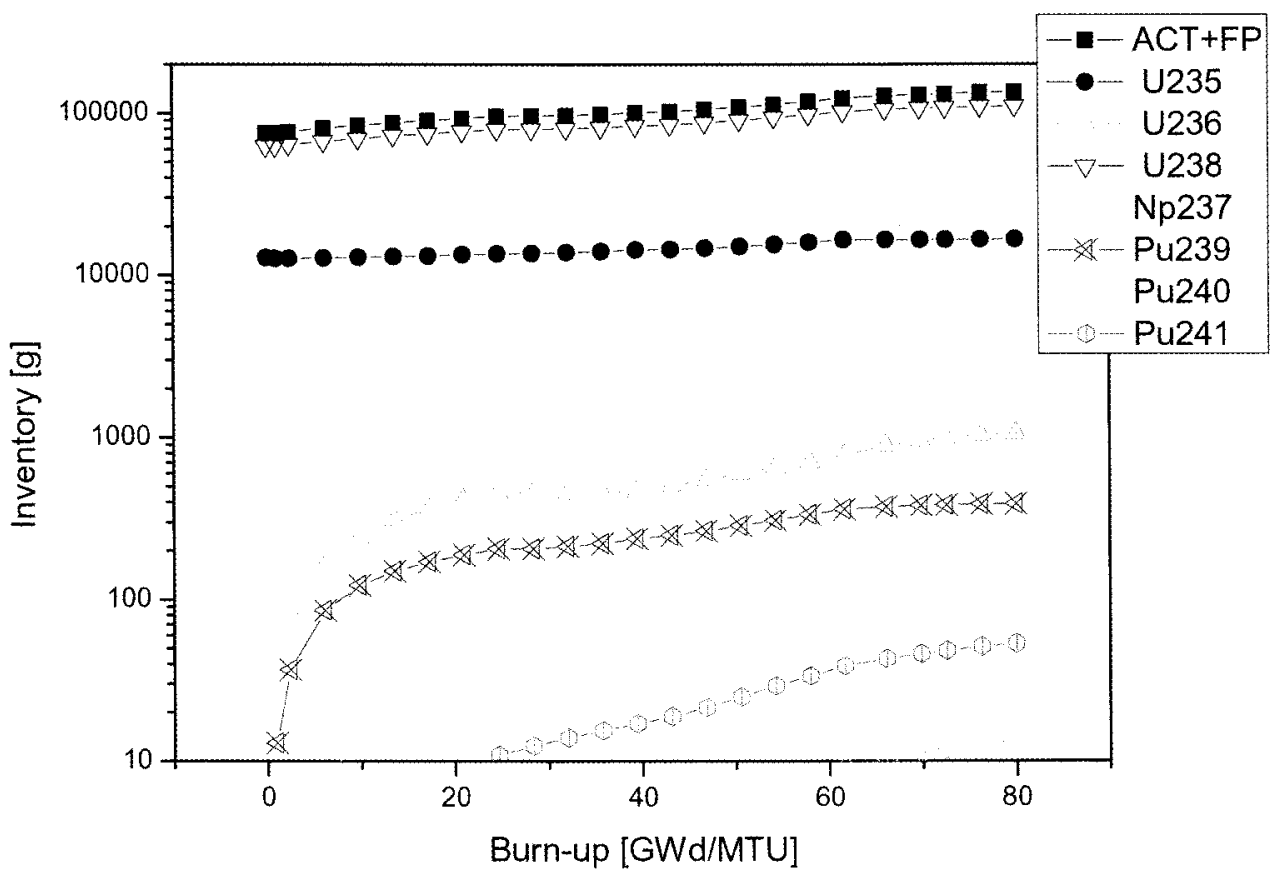

Fig. 8. The Variation of Inventory of Actinide and Fission Products with Time

approach the final convergence value or to a lack of balance in the ratio of the fuel feed and the discharge. It would be interesting to see that the initial peak when the burnup starts is the highest value of $\mathrm{k}_{\mathrm{eff}}$. In terms of neutronics, the dramatically steep peak should exist at the beginning, as an actual reactor is expected to operate smoothly and without problems.

The published inventory data for general HTGRs was difficult to gather. Over ten thousand documents were searched through using keywords for the source term and 
fission products. However, only one paper, by Liu and Cao [14], which is insufficient, contained relevant data for HTR-10. The inventories of each isotope in this work and the work by Liu are compared in Fig. 7.

The inventories of 22 nuclide isotopes were compared in relation to the end of the cycle in the equilibrium core of HTR-10. The reference inventory by Liu was calculated solely with ORIGEN2. However, the use of ORIGEN alone can cause erroneous results due to erroneous neutron cross-sections and flux information. Moreover, ORIGEN cannot reflect the variations in the fuel material with time.

Although the trend of the two curves in Fig. 7 appears to be similar, the difference from the two curves comes from Liu's misinterpretation with regard to the unique characteristics of the core itself. In short, this study highlights the need for further investigation due to the paucity of data available for comparison. A considerable amount of research must be conducted in the future.

\subsection{Actinide Inventory}

It is also possible to confirm from Fig. 8 that the inventories of actinides change as the burnup increases. There is also a rise in the number of actinides and fission products as the core becomes filled with fuel and the moderator is diminished. 22 actinides are traced, but the most of them are small and do not appear in the Figure.

Table 5 compares the actinides produced in the case of HTR-10 and Turkey point after approximately 380 days had passed. Turkey point is a pressurized water reactor (PWR), and the actinides generated in Turkey point can be calculated by ORIGEN-ARP [15]. By increasing the enrichment of ${ }^{235} \mathrm{U}$ in the case of HTGR, a higher burnup ratio can be achieved and the lower amount of spent material can be generated.

The remarkable point is the amount of isotopes of plutonium, which are perceived as the key issue in nonproliferation issues, in both cases. The most important is ${ }^{239} \mathrm{Pu}$ as the dominant factor in the determination of the plutonium level. The amount of plutonium in a HTGR is clearly lower than that in a PWR. The ratio of ${ }^{239} \mathrm{Pu}$ to the total actinides is $0.21 \%$ for a HTGR and $0.34 \%$ for a PWR, and the ratio of the total amount of plutonium isotopes according to a HTGR over a PWR is only $14 \%$. This reflects the fact that a higher enrichment fuel in a HTGR would be preferred to a lower enrichment fuel in a PWR in terms of proliferation resistance.

Regarding a HTGR, an in-depth study of spent fuel has not been done because the HTGR design of the generationIV type has not been determined. Therefore, the current work lays the foundation for future spent fuel analysis, providing an inventory of the actinides in fuel pebbles.

\subsection{Tritium in Coolant}

The variation of tritium inventory with time is shown in Fig. 9. This Figure shows that the activity of tritium in the coolant becomes stable after 400 effective full power
Table 5. Inventory of Actinides in each Equivalent Fuel Region Based on the Reactor Type

\begin{tabular}{c|c|c}
\hline Power & $10 \mathrm{MW} /$ total & $13.5 \mathrm{MW} / \mathrm{assembly}$ \\
\hline Reactor & HTGR & PWR \\
\hline enrichment & $17 \%$ & $2.56 \%$ \\
\hline At time [day] & 383 & 372 \\
\hline GWD/MTU & 28.37 & 9.48 \\
\hline U234 [g] & $1.506 \mathrm{E}-02$ & $8.937 \mathrm{E}+01$ \\
\hline U235 & $1.476 \mathrm{E}+04$ & $7.568 \mathrm{E}+03$ \\
\hline U236 & $4.720 \mathrm{E}+02$ & $7.751 \mathrm{E}+02$ \\
\hline U237 & $2.790 \mathrm{E}-01$ & $4.680 \mathrm{E}-03$ \\
\hline U238 & $8.527 \mathrm{E}+04$ & $4.411 \mathrm{E}+05$ \\
\hline U239 & $4.874 \mathrm{E}-02$ & $0.000 \mathrm{E}+00$ \\
\hline NP237 & $4.095 \mathrm{E}+00$ & $3.629 \mathrm{E}+01$ \\
\hline NP238 & $7.344 \mathrm{E}-03$ & $3.967 \mathrm{E}-09$ \\
\hline NP239 & $6.895 \mathrm{E}+00$ & $1.810 \mathrm{E}-06$ \\
\hline NP240 & $8.299 \mathrm{E}-05$ & $0.000 \mathrm{E}+00$ \\
\hline PU238 & $2.643 \mathrm{E}-01$ & $3.654 \mathrm{E}+00$ \\
\hline PU239 & $2.142 \mathrm{E}+02$ & $1.555 \mathrm{E}+03$ \\
\hline PU240 & $5.327 \mathrm{E}+01$ & $2.995 \mathrm{E}+02$ \\
\hline PU241 & $1.169 \mathrm{E}+01$ & $1.264 \mathrm{E}+02$ \\
\hline PU242 & $1.115 \mathrm{E}+00$ & $1.315 \mathrm{E}+01$ \\
\hline PU243 & $8.388 \mathrm{E}-05$ & $0.000 \mathrm{E}+00$ \\
\hline AM241 & $1.223 \mathrm{E}-01$ & $2.318 \mathrm{E}+00$ \\
\hline AM242 & $3.378 \mathrm{E}-04$ & $2.452 \mathrm{E}-07$ \\
\hline AM243 & $2.177 \mathrm{E}-02$ & $7.067 \mathrm{E}-01$ \\
\hline CM242 & $1.848 \mathrm{E}-02$ & $1.207 \mathrm{E}-01$ \\
\hline CM243 & $4.914 \mathrm{E}-05$ & $1.026 \mathrm{E}-03$ \\
\hline CM244 & $1.413 \mathrm{E}-03$ & $4.791 \mathrm{E}-02$ \\
\hline Total [g] & $1.008 \mathrm{E}+05$ & $4.516 \mathrm{E}+05$ \\
\hline & & \\
\hline
\end{tabular}

days (EFPD). It then gradually decreases and settles at approximately $8.07 \times 10^{9}\left[\mathrm{~Bq} / \mathrm{m}^{3}\right]$ eventually. There are two studies concerning the tritium inventory in the primary coolant of HTR-10 at the end of the cycle; the results of both are compared in Table 6. As mentioned in section 2.4 the main factors affecting tritium generation are the activation cross-section and the neutron flux. The estimation of the neutron flux shown in Fig. 7 is feasible, and the activation cross-sections are constants embedded in ORIGEN2. Therefore, the difference in the results of the current and earlier works may only stem from the conditions rather than the method. In Liu's work [14], helium 


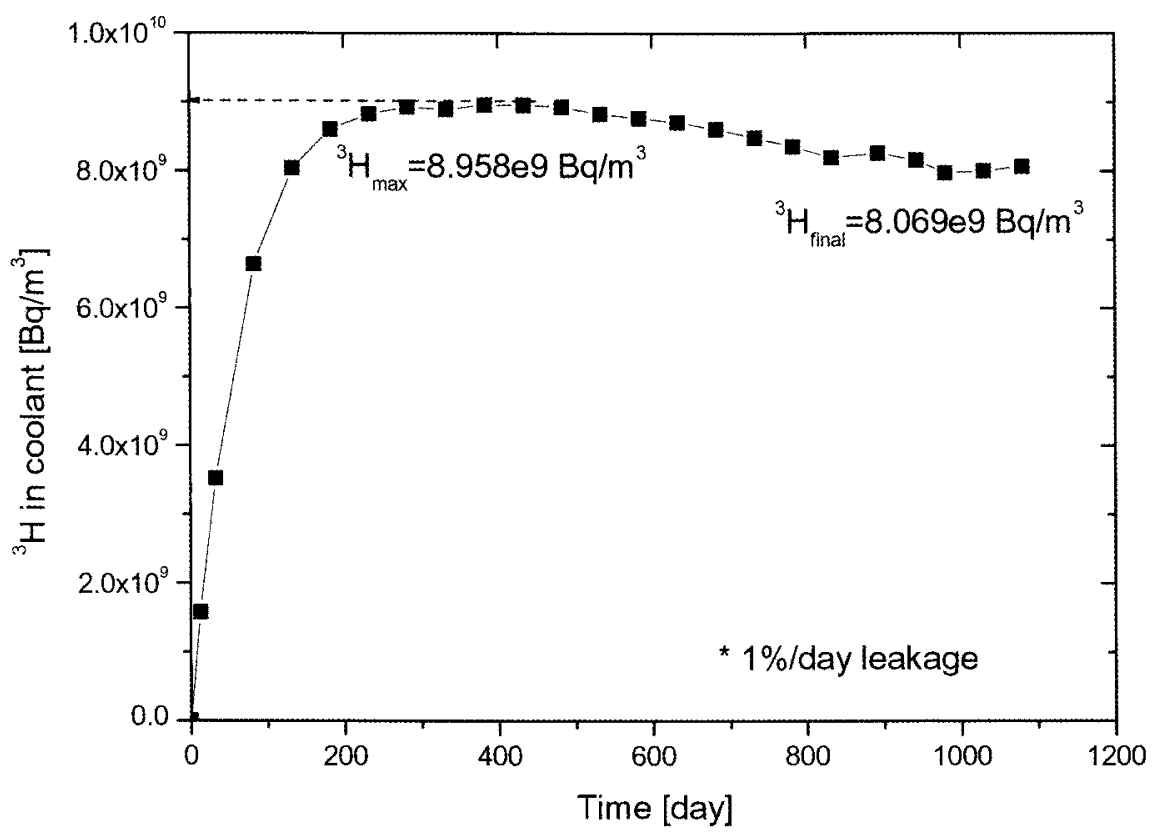

Fig. 9. The Inventory of Tritium Variation with Time

Table 6. Inventory of Tritium in the Primary Coolant at the End of the Cycle

\begin{tabular}{c|c}
\hline & ${ }^{3} \mathrm{H}\left[\mathrm{Bq} / \mathrm{m}^{3}\right]$ \\
\hline KAIST & $8.07 \times 10^{9}$ \\
\hline Liu, 2002 [14] & $6.10 \times 10^{9 *}$ \\
\hline Liu, 1998 [16] & $7.50 \times 10^{7}$ \\
\hline
\end{tabular}

" assumed that the total coolant volume was $93.5 \mathrm{~m}^{3}$

purification systems were used. In addition, only tritium by ternary fission and its diffusion were taken into account. This made the inventory lower compared to the result of the current work. There is no description of the inventory by Liu [16]. In addition, the tritium generated in the coolant appears to be overestimated because the helium purification system and permeation are not considered in this study. The effect of introducing a helium purification system will be investigated in a future study.

\section{DISCUSSION}

It is known that the neutron streaming effect in the coolant channels should be considered in neutronics. It is necessary to quantify the influence of a streaming neutron on the core reactivity, which provides a guideline for the treatment of a streaming effect. However, the neutron streaming effect was estimated to be less than $67 \mathrm{pcm}$ in
Table 7. The Value of $k_{\text {eff }}$ is Dependent on the Temperature in a Helium Atmosphere [8]

\begin{tabular}{c|c|c|c}
\hline $\mathrm{T}\left[{ }^{\circ} \mathrm{C}\right]$ & INET & FZJ & NRG \\
\hline 20 & 1.11975 & 1.12665 & 1.11759 \\
\hline 120 & 1.11044 & 1.11331 & 1.10846 \\
\hline 250 & 1.09596 & 1.09588 & 1.09629 \\
\hline
\end{tabular}

a previous study [17]. The neutron streaming effect on reactivity appears to be insignificant and is thus disregarded in the reactor physics analysis for the HTGR core.

In the present work, although considerable effort was made to obtain accurate data, the task of formulating an exact inventory is fraught with difficulties. For example, the reactivity could not be kept constant and no consideration was given to reactivity control or neutron absorber balls. The lack of reactivity control can have an effect on the generation of fission products over time. However, its effect would be small enough to disregard in this study because the fission reaction rate is mainly related to power and not to reactivity. Second, cross-sections for adjusting to the conditions of actual reactors must be provided; these can be generated using the NJOY code for different temperatures with an existing library, such as an evaluated nuclear data file (ENDF). However, generating a crosssection was not discussed here, and the cross-sections used in this study had a default temperature of $300 \mathrm{~K}$. The temperature dependence of $k_{\text {eff }}$ at under full loading is 
listed in Table 7 along with the compensation. Third, there is uncertainty over the feed-discharge rate; the continual process of fuel feeding and discharging is impossible to describe precisely. These four problems need to be explored in the future but are beyond the scope of the present paper. Further studies are needed on different large-scale assessments.

\section{CONCULUSION}

This article has attempted to sketch out the main method and provide fundamental information related to source terms from which safety assessment would start. It should be stressed that an evaluation of the source term inventory is the first step to be done for nuclear safety.

The main purpose of this work was to explore the source term inventory in a HTGR, particularly a PBR. With help of the combined codes of MCNP, ORIGEN, MONTEBURNS, the author has attempted to obtain the inventory. Regarding the core modeling, the code of MCNP was employed using the BCC lattice, as used in previous studies. Based on the modeling, the generation of fission products with an increase in the burnup amount was simulated. Unfortunately, there are few reference studies available, but the results of the current study seem highly probable. The inventory of actinides in a fuel pebble was also investigated and compared to that in a PWR. The results show a HTGR is more attractive in terms of spent fuel management because the amount of fuel required for the same power is less. It would be informative to take into account an analysis of the spent fuel. Proceeding from this fact, one could logically assume that this inventory simulation is applicable to future spent fuel management schemes, as it provides information pertaining to actinides and fission products. In addition, this paper investigated the inventory of tritium in the coolant. The result implies that coolant purification methods should be improved.

As the actual source-term inventories in HTR-10 are not published, unfortunately, the paucity of references compared to the current work leaves a considerable amount of uncertainty. Although an exact FP inventory could not be obtained due to the uncertainty associated with reactor operation and fuel management, it is hoped that this work will serve as a platform from which an analysis of the source term in HTGR may be undertaken in the future.

\section{ACKNOWLEDGMENTS}

This study was carried out under National Research Laboratory (NRL) for the 'Development of Safety Analysis
Tools for Hydrogen Production High-temperature Gascooled Reactors' in Korea.

\section{REFERENCES}

[ 1 ] Morris, R.N., Petti, D.A., Powers, D.A., and Boyack, B.E., "TRISO-Coated Particle Fuel Phenomenon Identification and Ranking Tables (PIRTs) for Fission Product Transport Due to Manufacturing, Operations, and Accidents", NUREG/CR-6844, Vol.1, US-NRC (2004).

[2] Soffer, L., Burson, S.B., Ferrell, C.M., Lee, R.Y., and Ridgely, J.N., "Accident Source Terms for Light Water Nuclear Power Plants," NUREG-1465, US-NRC (1995).

[ 3 ] Feltus, M.A., "ANS Gas Reactor Training Course - Gas Reactor Core, Physics," ANS Meeting (2003).

[4] Chen, J., "On-line Interrogation of Pebble Bed Reactor Fuel using Passive Gamma-ray Spectrometry," Doctoral dissertation, University of Cincinnati (2004).

[5] Briesmeister, J.F., "MCNP - A General Monte Carlo NParticle Transport Code," Version 4C, LA-13709-M (2000).

[6] Croff, A.G., "A User's Manual for the ORIGEN2 Computer Code," ORNL/TM-7175 (1980).

[7] Trellue, H. R., Poston, D.I., "User's Manual Version 2.0 for Monteburns," Version 5B, LANL preprint LA-UR-99$4999(2000)$.

[ 8 ] IAEA, "Evaluation of High Temperature Gas Cooled Reactor Performance: Benchmark Analysis related to Initial Testing of the HTTR and HTR-10," TECDOC-1382, IAEA (2003).

[9] Yang, Y., Luo, Z., Jing, X., Wu, Z., "Fuel Management of the HTR-10 Including the Equilibrium State and the Running-in Phase," Nuclear Engineering Design, 218, pp. 33-41(2002).

[10] Benedict, M., Pigford, T.H., Levi, H.W., Nuclear Chemical Engineering, McGraw-Hill Book Company, US (1981).

[11] Terry, W.K. et al., "Evaluation of the HTR-10 Reactor as a Benchmark for Physics Code QA," PHYSOR-2006, INL/CON-06-11699 (2006).

[12] Yao, M.S. et al., "The Helium Purification System of the HTR-10," Nuclear Engineering and Design, 218, pp. 163$167(2003)$.

[13] Seker, V., Colakm, U., "HTR-10 Full Core First Criticality Analysis with MCNP," Nuclear Eng. and Design, 222, pp. 263-270 (2003).

[14] Liu, Y., Cao J., "Fission Product Release and its Environment Impact for Normal Reactor Operations and for Relevant Accidents," Nuclear Eng. and Design, 218, pp. $81-90$ (2002).

[15] Bowman S.M., Leal, L.C., ORIGEN-ARP: Automatic Rapid Process for Spent Fuel Depletion, Decay, and Source Term Analysis, Vol. 1, Section D1, NUREG/CR-0200 (2000).

[16] Liu, Y, "Radioactive Release and Dose Calculations for the HTR-10," Nuclear Technology, 124, pp. 192-197 (1998).

[17] Kim, K.S. et al., "Development of a Physics Analysis Procedure for the Prismatic Very High Temperature Gascooled Reactors," annals of Nuclear Energy, 34, pp. 849860 (2007). 